\title{
PENGEMBANGAN STANDAR NASIONAL INDONESIA PRODUK PELONTAR SATELIT KUBUS BERBASIS TAB BERDASARKAN ISO 17770:2017
}

\author{
Indonesia Nasional StandardDevelopment of the Tab-Based Deployer CubeSatellite \\ Products Based on ISO 17770:2017
}

\author{
Dwi Risdianto \\ Pusat Inovasi dan Standar Penerbangan dan Antariksa, Lembaga Penerbangan dan Antariksa Nasional \\ JI. Pemuda Persil No. 1, Jakarta 13220, DKI, Jakarta, Indonesia \\ e-mail:risdiantomas78@gmail.com
}

\begin{abstract}
Abstrak
Pesatnyapenggunaansatelit kubus $6 \mathrm{U}$ dan12U untuk misi ekplorasi ruang angkasadan pemantauan bumi berbiaya murah dalam lima tahun terakhir mendorong industri komponen satelit kubusdiberbagai negara termasuk di Indonesia. Pemerintah Indonesia melalui Undang-Undang No. 21 Tahun 2013 tentang Keantariksaan mendorong terwujudnya industri keantariksaan yang menghasilkan produk yang memenuhi kebutuhan nasional yang sesuai standar sehingga dapat bersaing dengan produk negara lain. Standar satelit kubus telah ditetapkan dalam ISO 17770:2017namun belum mencakup spesifikasi pelontar satelit kubus berbasis tab, untuk itu diperlukan kaji ulang standar satelit kubus agar selaras dengan perkembangan teknologi saat ini.Tujuan penelitian ini adalah untuk mengidentifikasi kebutuhan standarproduk pelontar satelit kubus berbasis tab.Metode penelitian menggunakan Framework for Analysis Comparison and Testing Standard (FACTS)yaitu menganalisis parameter teknis yang dibutuhkan stakeholder, perbandingan parameter teknis standar acuan dan validasiparameter teknis. Hasil penelitian menunjukan terdapat empat parameter teknis yang prioritas diusulkan menjadi standar pelontar satelit kubus berbasis tab, yaitu spesifikasi dimensi, spesifikasisistem pelontaran, spesifikasisistem kelistrikan dan spesifikasi material pelontar .
\end{abstract}

Kata kunci: Standar Nasional Indonesia, pelontar satelit kubus, satelit kubus 6U, FACTS.

\begin{abstract}
The rapid used of $6 U$ and $12 U$ cube satellites for space exploration missions and low-cost earth monitoring in the last five years are pushing the industrialization of cube satellite components in various countries, including in Indonesia.The Government of Indonesia through space Law No. 21 of2013 encourages the realization of the space industry which is produces the products that meet national needs and according to standards so that they can compete with other countries' products. Standards for cube satellite specifications are publish in ISO 17770: 2017 but do not include tab-based cube satellite deployer specifications, for this reason a review of cube satellite standards needed to be in line with current technology. The purpose of this research is to identify the standards needed for tab-based deployer cube satellite products. This research uses the FACTS method (Framework for Analysis Comparison and Testing Standard which is analyzing technical needs, comparison of standards and technical parameters validating. There are four standard parametersthat will be developed intostandards for tabbased deployer cube satellite products, namely dimensios specification, deploy system, deployer electrical system, and material deployer spesification
\end{abstract}

Kata kunci: Indonesia Nasional Standard, cube satellite deployer, cube satellite 6U, FACTS

\section{PENDAHULUAN}

Dalam lima tahun terakhir jumlah peluncuran satelit kubus meningkat di berbagai negara seiring dengan berkembangnya misi eksplorasi ruang angkasa dan pemantauan bumi berbiaya murah. Satelit kubus (cubesat) adalah satelit kecil berbentuk kubus berukuran $10 \times 10 \times 10 \mathrm{~cm}$ dengan berat maksimum $1,33 \mathrm{~kg}$ atau disebut $1 \mathrm{U}$ yang dibuat oleh California Polytechnic State University (Cal Poly's) pada tahun 1999 yang ditujukan untuk pendidikan dan penelitianruang angkasa (Tullino,2017).Setelah satelit kubus pertama berhasil diluncurkan pada orbit rendah di tahun 2000banyak negara yang tertarik mengembangkan satelit kubus. Saat ini pengembang satelit kubus bukan hanya dari perguruan tinggi saja,tetapi sudah dilakukan oleh institusi litbang, lembaga keantariksaan dan juga industri keantariksaan diberbagai negara.Peningkatan jumlah peluncuran satelit kubus dalam lima tahun terakhir ditunjukan pada Gambar 1. 


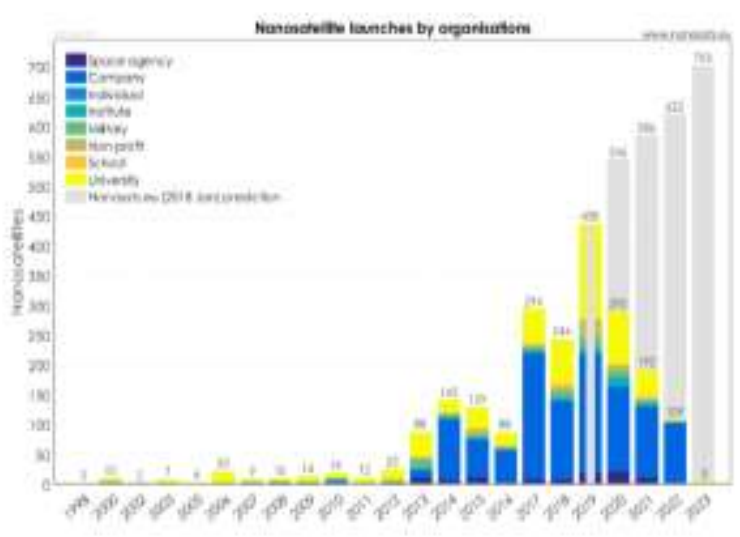

Gambar 1 Statistikpeluncuran satelit kubus.(sumber: Erik Kulu, Nanosats database, www.nanosats.eu)

Pesatnya pemanfaatan satelit kubus oleh berbagai sektor memicu permintaan pasar terhadap satelit kubusyang berdampak kepada industrialisasi komponen satelit kubus.Pelontar merupakan komponenpenting dari satelit kubus. Pelontar satelit merupakanantarmuka satelit kubus dengan wahana peluncur yang berfungsi melindungi payload satelit dari interferensi mekanik, elektrikdan elektromagnetik selama fase peluncuran (Puig-Suari, 2001).

Pengembangan satelit kubus di Indonesia dimulai pada tahun 2008, dan popular ditahun 2011 dengan terciptanya INASAT-1 (Indonesia Nano Satelit-1) hasil konsorsium LAPAN bersama enam Perguruan Tinggi Indonesia. Melalui Undang-Undang No. 21 Tahun 2013 tentang Keantariksaan, Pemerintah Indonesia mendorong terwujudnya industri keantariksaan yang menghasilkan produk yang memenuhi kebutuhan nasional dan sesuai standar sehingga dapat bersaing dengan produk negara lain.

Berkembangnya industri komponen satelit kubus memunculkan kebutuhan standar industri terkait spesifikasi komponen satelit kubus,termasuk didalamnya standar pelontar satelit kubus. Badan standardisasi internasional, ISO telah menetapkan standar satelit kubus yang tercantum dalam ISO 17770:2017namun belum mencakup standardisasi sistem pelontar satelit kubus berbasis tab.Seiring berkembangnya teknologi dan kebutuhan ekplorasi ruang angkasa yang lebih komplek, saat ini banyak dikembangkan berbagai tipe satelit kubus yaitu $6 \mathrm{U}, 12 \mathrm{U}$ dan $16 \mathrm{U}$ dengan sistem pelontar berbasis tab(Holemans, William, 2014).Untuk itu diperlukan kaji ulang standar satelit kubus agar harmonis dengan perkembangan teknologi saat ini.Jumlah peluncuran satelit kubus berbagai tipe dapat dilihat pada Gambar 2.

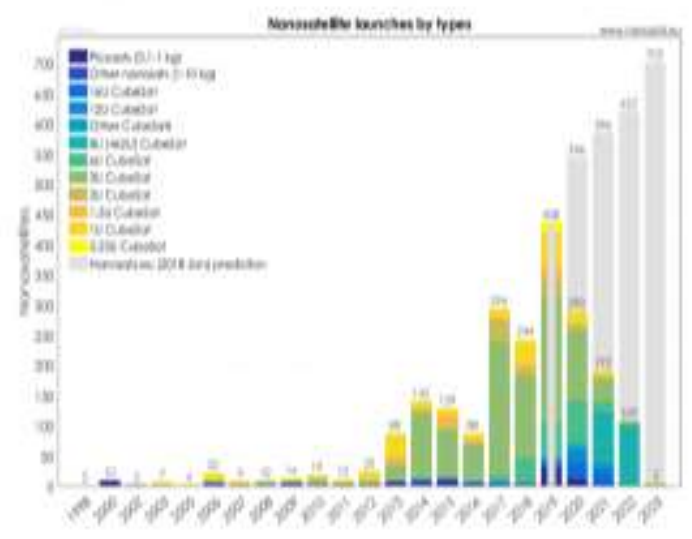

Gambar 2 Statistikpeluncuran tipe satelit kubus.(sumber: Erik Kulu, Nanosats database, www.nanosats.eu)

Pengembangan standar produk nasional suatu negara umumnya mengacu ke standar internasional seperti ISO, IEC atau ASTM.Harmonisasi dengan standar internasionalpenting untuk mengurangi hambatan teknis nontariff, mendukung perdagangan multilateral yangakan memudahkan produsen dan lembaga penilaian kesesuaian yang melakukan pengujian (Pribadi, 2012).

Ada dua aspek yang penting dalam standar produk, yaitu keamanan dan performansi.Faktor keamanan produk diperoleh dari pemenuhan persyaratanpersyaratan teknis yang ditetapkan, sedangkan performansi merupakan kemampuan unjuk kerja berdasarkan spesifikasi yang ditetapkan (Mandaris, 2011). Dalam standar ISO 17770:2017 disebutkan persyaratan teknis mekanik, elektrik dan performansi yang harus dipenuhi oleh pelontar satelit kubus berbasis rel $1 U$ dan $3 U$, yang tentu saja akan berdampak kepada perbedaan desain dan spesifikasi pada pelontar satelit berbasis tab $6 \mathrm{U}$ dan $12 \mathrm{U}$.

Oleh karena itu, penelitian ini dikhususkan untuk mengidentifikasikebutuhan spesifikasi teknis dan performansi yang disyaratkan untuk pelontar satelit kubus berbasis tab sebagai bahan usulan Rancangan Standar Nasional Indonesia (RSNI)dalam rangka menjamin mutu produk pelontar satelit kubus. 


\section{TINJAUAN PUSTAKA}

\section{a. Pelontar Satelit Kubus}

Pelontar satelit kubus merupakan wadah kotak pembungkus satelit kubus dengan pintu penutup disatu sisi yang berfungsi sebagai terminal lontar. Pelontar juga merupakan antarmuka satelit kubus dengan wahana peluncur yang berfungsi melindungi keamanan payload satelit dari interferensi mekanik wahana peluncur pada fase peluncuran (Nason,2002). Secara umum, pelontar dibagi menjadi 2(dua) jenis, yaitu pelontar satelit berbasis rel dan pelontar satelit berbasis tab. Pelontar berbasis tab adalah pelontar yang menggunakan dua rel yang tipis yang dicengkramkan pada plat pelontar untuk menjalankan mekanisme pelontaran mirip dengan fungsi kaliper rem dan rotor mobil (Hevner, 2011). Pelontar satelit kubus berbasis tab ditunjukan pada Gambar 3.

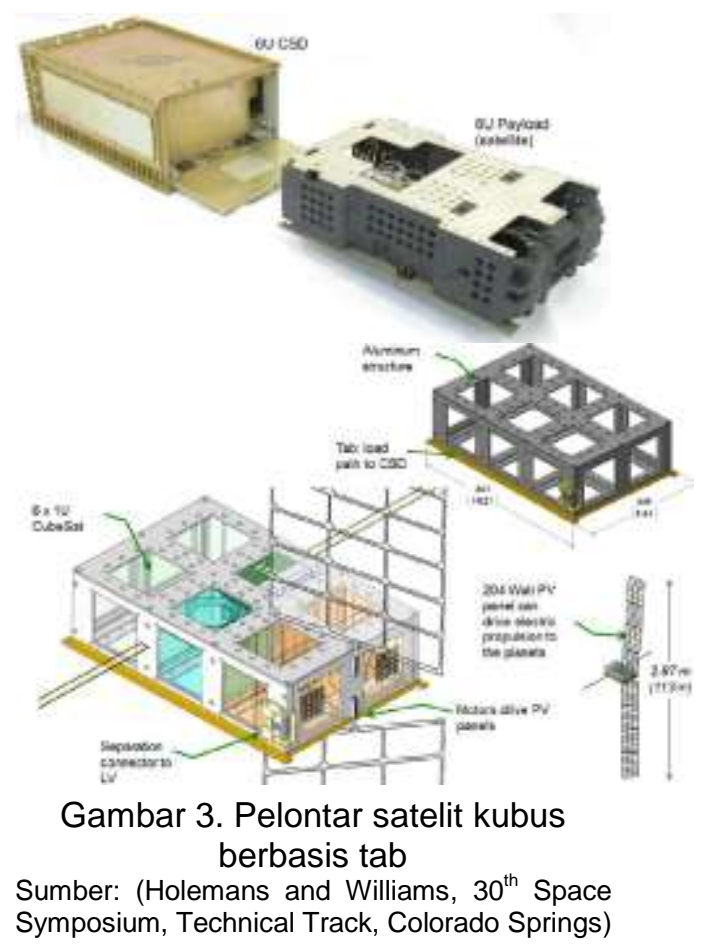

\section{b. Tipe satelit kubus}

Pada tahun 2000, satelit kubus pertama berhasil diluncurkan pada orbit rendah $200-500 \mathrm{~km}$ diatas bumi dengan ukuran $10 \mathrm{~cm} \times 10 \mathrm{~cm} \times 10 \mathrm{~cm}$ dengan berat $1 \mathrm{~kg}$ yang disebut dengan $1 \mathrm{U}$ yang kemudian menjadi standar sebuah satelit kubus. Sepanjang tahun 2000 sampai dengan 2013 satelit kubus mengalami perkembangan secara dimensi menjadi $2 \mathrm{U}$ dan 3U. Perkembangan tipe satelit ini terletak pada susunan atau konfigurasi satelit kubus $1 \mathrm{U}$ yang disusun secara seri terhadap sumbu lateralnya dengan berat maksimum 3kg. Sejak tahun 2014, mulai dikembangkan satelit kubus $6 \mathrm{U}$ dengan sistem pelontar berbasis Tab. Tipe $6 \mathrm{U}$ merupakan satelit kubus $3 \mathrm{U}$ yang disusun secara paralel terhadap sumbu lateralnya dengan berat maksimum $12 \mathrm{~kg}$. Tipe satelit kubus ditunjukan pada Gambar 4.

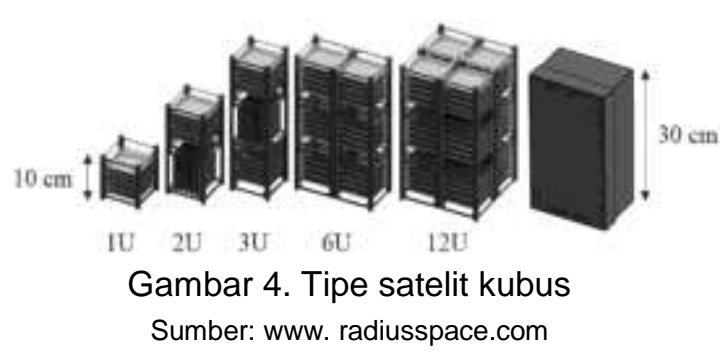

\section{c. Pengembangan standar nasional}

Pengembangan standar produk nasional suatu negara umumnya mengacu ke standar internasional seperti ISO, IEC atau ASTM. Agar harmonisasi dengan standar internasional. Standar internasional terkait satelit kubus dan pelontarnya telah dirumuskan oleh ISO melalui Technical Committee (TC) 20 - aircraft and space vehicles pada tahun 2017 yang dipublikasikan dalam dokumen ISO 17770:2017.Standar ini menetapkan beberapa persyaratan teknis untuk menjamin kualitas satelit kubus, pelontar satelit dan cara uji untuk satelit kubus kelas piko berbasis rel (ISO 17770, 2017).

Suatu standar termasuk ISO 17770:2017, sejalan dengan implementasinya harus terus disesuaikan dengan kemajuan teknologi dan kemampuan industri yang menerapkannya (Pusaka, 2011). ISO 17770:2017 hanya dapat diterapkan pada satelit kubus tipe $1 \mathrm{U}, 2 \mathrm{U}, 3 \mathrm{U}$ dengan sistem pelontar menggunakan mekanisme pegas dan rel.Seiring dengan peningkatan penggunaan satelit kubus dan kemajuan teknologi satelit nano untuk eksplorasi ruang angkasaperlu dilakukan kaji ulang strandar. Dengan demikian kegiatan kaji ulang merupakan aktivitas penyempurnaan standar yang terus berlanjut.

\section{d. Kebijakan industri keantariksaan nasional}

Trend yang berkembang di internasional dalam lima tahun terakhir 
adalah penggunaan satelit kubus tipe $6 \mathrm{U}$ dan $12 \mathrm{U}$ dengan berat $12 \mathrm{~kg}$ untuk pengembangan teknologi antariksa, komunikasi, navigasi dan pengamatan bumi memicu tumbuhnya Industri manufaktur komponen satelit nano secara global (Pratt, Balakrishnan,2015). Pemerintah Indonesia sendiri berkomitmen untuk mendukung terwujudnya industri keantariksaan yang berdaya saing melalui terbitnya UU Nomor 21 tahun 2013 tentang keantariksaan. UU Nomor 21 tahun 2013 bertujuanmewujudkan kemandirian dan meningkatkan daya saing bangsa dan negara dalam penyelenggaraan keantariksaan dengan terwujudnya industri kerekayasaan dan jasa keantariksaan untuk menghasilkan produk yang dapat memenuhi kebutuhan nasional dan ekspor yang dapat bersaing dengan produk negara lain.

Untuk dapat menghasilkan produk yang berdaya saing, produk harus sesuai dengan standar. Standar Nasional Indonesia (SNI) merupakan satu alat untuk meningkatkan mutu,efisiensi produksi dan memperlancar transaksi perdagangan yang sehat dan transparan. Hal ini juga sejalan dengan kebijakan Pemerintah terkait menumbuhkan komersialisasi keantariksaan dengan melibatkan pelaku usaha, badan usaha milik negara, industri dan swasta yang tertuang dalam Peraturan Presiden nomor 45 tahun 2017 tentang Rencana Induk Penyelenggaraan Keantariksaan 2016-2040.

\section{METODE PENELITIAN}

Proses pengembangan standar produk dimulai dengan identifikasi parameter spesifikasi teknis yang dipersyaratkan untuk memenuhi aspek keamanan dan performansi. Penelitian ini menggunakan metode analisis FACTS (Framework for Analysis Comparison and Testing Standard )untuk mengidentifikasi parameter teknis yang diprioritaskan menjadi menjadi standar melalui pembandingan persyaratan teknis yang ada dalam ISO 1770:2017 sebagai standar acuan dengan hasil analisis parameter teknis yang dibutuhkan oleh stakeholder.

Data primer parameter teknis yang dibutuhkan stakeholderdiperoleh melalui wawancara mendalam dengan para perekayasa dan penelitidi bidang teknologi satelit.Data sekunder terkait parameterparameter teknis pelontar satelit diambil dari studi pustaka ISO 1770:2017, dokumen teknis desain pelontar satelit kubus dan laporan hasil penelitian yang terkait.

4. HASIL DAN PEMBAHASAN

a. Analisis Parameter Teknis berdasarkan Kebutuhan Stakeholder

Berdasarkan hasil wawancara terhadap 20 respondendengan 4 pertanyaan kunci berdasarkan persyaratan teknis ISO1770:2017diperoleh prioritas parameterteknis yang disyaratkan dalam produk pelontar satelitkubus berbasis tabsebagai berikut:

Tabel 1. Kebutuhan parameter teknis pelontar satelit kubus berbasis tab

\begin{tabular}{|c|c|c|}
\hline Pertanyaan & $\begin{array}{l}\text { Indikatorpara } \\
\text { meter }\end{array}$ & $\begin{array}{c}\text { Bobot } \\
\text { priorita } \\
\text { s }\end{array}$ \\
\hline \multirow{4}{*}{$\begin{array}{l}\text { Jika aspek } \\
\text { keamanan } \\
\text { menjadi nilai ukur } \\
\text { jaminan mutu } \\
\text { produk pelontar } \\
\text { maka parameter } \\
\text { teknis apa saja } \\
\text { yang perlu untuk } \\
\text { distandarkan }\end{array}$} & Dimensi & $50 \%$ \\
\hline & Material & $5 \%$ \\
\hline & $\begin{array}{l}\text { Sistem } \\
\text { Pelontaran }\end{array}$ & $30 \%$ \\
\hline & $\begin{array}{l}\text { Sistem } \\
\text { kelistrikan }\end{array}$ & $15 \%$ \\
\hline \multirow{4}{*}{$\begin{array}{l}\text { Dari parameter } \\
\text { keamanan yang } \\
\text { dipersyaratkan di } \\
\text { atas manakah } \\
\text { yang memiliki } \\
\text { probabilitas tinggi } \\
\text { menjadi akar } \\
\text { masalah dari } \\
\text { ketidaksesuaian } \\
\text { produk }\end{array}$} & Dimensi & $50 \%$ \\
\hline & Material & $5 \%$ \\
\hline & $\begin{array}{l}\text { Sistem } \\
\text { pelontaran }\end{array}$ & $30 \%$ \\
\hline & $\begin{array}{l}\text { Sistem } \\
\text { kelistrikan }\end{array}$ & $15 \%$ \\
\hline \multirow{3}{*}{$\begin{array}{l}\text { Jika faktor } \\
\text { performansi } \\
\text { menjadi nilai ukur } \\
\text { jaminan mutu } \\
\text { produk pelontar } \\
\text { maka parameter } \\
\text { unjuk kerja apa } \\
\text { saja yang } \\
\text { dipersyaratkan } \\
\text { untuk diuji }\end{array}$} & $\begin{array}{l}\text { Kompatibelita } \\
\text { s kapasitas } \\
\text { kompartemen } \\
\text { pelontar }\end{array}$ & $50 \%$ \\
\hline & $\begin{array}{l}\text { Ketahanan } \\
\text { material } \\
\text { pelontar } \\
\text { terhadap } \\
\text { pemenuhan } \\
\text { kriteria } \\
\text { outgassing }\end{array}$ & $5 \%$ \\
\hline & $\begin{array}{l}\text { Efektifitas } \\
\text { pelontaran } \\
\text { secara } \\
\text { elektrik } \\
\end{array}$ & $30 \%$ \\
\hline
\end{tabular}




\begin{tabular}{|c|c|c|}
\hline Pertanyaan & $\begin{array}{l}\text { Indikatorpara } \\
\text { meter }\end{array}$ & $\begin{array}{c}\text { Bobot } \\
\text { priorita } \\
\text { s }\end{array}$ \\
\hline & $\begin{array}{l}\text { Besar arus } \\
\text { listrik dan } \\
\text { tegangan } \\
\text { kerja konektor } \\
\text { separasi }\end{array}$ & $15 \%$ \\
\hline \multirow{4}{*}{$\begin{array}{l}\text { Dari parameter } \\
\text { performansi yang } \\
\text { dipersyaratkan } \\
\text { diatas manakah } \\
\text { yang memiliki } \\
\text { probabilitas tinggi } \\
\text { menjadi akar } \\
\text { masalah dari } \\
\text { ketidaksesuaian } \\
\text { unjuk kerja }\end{array}$} & $\begin{array}{l}\text { Kompatibelita } \\
\text { s kapasitas } \\
\text { kompartemen } \\
\text { pelontar }\end{array}$ & $50 \%$ \\
\hline & $\begin{array}{l}\text { Ketahanan } \\
\text { material } \\
\text { pelontar } \\
\text { terhadap } \\
\text { pemenuhan } \\
\text { kriteria } \\
\text { outgassing }\end{array}$ & $5 \%$ \\
\hline & $\begin{array}{l}\text { Efektifitas } \\
\text { pelontaran } \\
\text { secara } \\
\text { elektrik }\end{array}$ & $30 \%$ \\
\hline & $\begin{array}{l}\text { Besar arus } \\
\text { listrik dan } \\
\text { tegangan } \\
\text { kerja konektor } \\
\text { separasi }\end{array}$ & $15 \%$ \\
\hline
\end{tabular}

Sumber: data diolah,2018

Hasil pengolahan data menunjukan bahwa $50 \%$ spesifikasi teknis dimensi pelontar yang meliputi panjang, lebar,dan tinggi menjadi prioritas untuk distandarkan. Hal ini dikarenakan fungsi dari pelontar sendiri yang merupakan wadah untukmembungkus seluruh bagian satelit kubus sehingga satelit kubus dengan mudah diintegrasikan kedalam kompartemen wahana peluncur.Sebagai komponen antarmuka satelit kubus dengan wahana peluncur, pelontar satelit harus dapat melindungi payload satelit dari interferensi mekanik, elektrik dan elektromagnetik selama fase peluncuran. Kondisi ketidaksesuaian dimensi pelontarini yang menurut beberapa perekayasa dan peneliti teknologi satelit akan menyebabkan kegagalan integrasi satelit kubus kedalam kompartemen pelontar yang berdampak kepada keamanan satelit kubus, selain itu juga akan menambah biaya dan waktu desain serta fabrikasi produk pelontar satelit.

Hasil wawancara juga memperlihatkan sebanyak $30 \%$ pengembang satelit kubus mensyaratkan spesifikasi sistem pelontaran untuk distandarkan. Hal ini memperlihatkan secara prinsip pelontaran satelit sama tetapi secara teknis sistem pelontaran satelit kubus berbasis tab yang menggunakan tabdan aktuator berbeda dengan mekanismepelontaran menggunakanrel dan pegas pada pelontar satelit kubus berbasis rel.Kondisi ini yang menurut praktisi satelit kubus berdampak kepada performansi masing-masing tipe pelontar.

Di sisi lain, ditinjau dari sudut pandang performansi pelontar satelit berbasis tab maka $20 \%$ perekayasa dan peneliti teknologi satelit mengusulkan standar unjuk kerja sistem kelistrikan. Fokus dari standardisasi sistem kelistrikan ini bagaimana menyediakan arus listrik dan tegangan kerja yang efektif untuk menjalankan separasi sehingga berdampak kepada penyediaan komponen elektronik yang standar.

Hasil wawancara dengan perekayasa dan peneliti bidang teknologi satelit menyatakan bahwa dalam mengembangkan satelit kubus dan pelontarnya mereka sudah mengacu kepada material yang ditetapkan dalam standar ISO 17770:2017. Mereka sangat yakin bahwa material yang terdapat dalam standar tersebut dapat menjamin keamanan satelit dari kerusakan struktur akibat proses outgassing dan interferensi elektromagnetik. Meskipun demikian sebanyak $10 \%$ peneliti masih mengusulkan spesifikasi material untuk pelontar satelit kubus berbasis tab berdasarkan hasil pengujian sebagai penjamin mutu produk. Hal ini mungkin dikarenakan adanya pengembangan metode uji dan proses pengambilan sampel yang perlu dievaluasi.

\section{b. Analisis perbandingan standar}

Perbandingan standar dilakukan dengan membandingkan persyaratan teknis yang ada dalam standar acuan dengan kebutuhan spesifikasi teknis stakeholder sehingga diketahui persyaratan teknis apa yang berpengaruh terhadap kebutuhan stakeholder yang belum diatur dalam standar acuan (Pratiwi, at all,2018).

Standar acuan yang dibandingkan adalah ISO 17770:2017, dan dokumen teknis Caniterized Satellite Dispencer (CSD6U data sheet). Berdasarkan studi literatur hasil perbandingan standar ditunjukan pada Tabel 2. 
Tabel 2 Perbandingan standar acuan dengan kebutuhan stakeholder

\begin{tabular}{|c|c|c|}
\hline $\begin{array}{l}\text { Parameter } \\
\text { teknis } \\
\text { kebutuhan } \\
\text { stakeholder }\end{array}$ & $\begin{array}{l}\text { Parameter } \\
\text { teknis } \\
\text { ISO17770:2017 }\end{array}$ & $\begin{array}{l}\text { Perameter } \\
\text { teknis } \\
\text { dokumen } \\
\text { teknis } \\
\text { CSDdata } \\
\text { sheet }\end{array}$ \\
\hline $\begin{array}{l}\text { Spesifikasi } \\
\text { dimensi } \\
\text { pelontar } \\
\text { satelit } \\
\text { berbasis } \\
\text { tab }\end{array}$ & $\begin{array}{l}\text { Dimensi } \\
\text { pelontar Rel } \\
3 \mathrm{U} \\
\mathrm{P}=340 \mathrm{~mm} \\
\mathrm{~L}=113 \mathrm{~mm} \\
\mathrm{~T}=113 \mathrm{~mm}\end{array}$ & $\begin{array}{l}\text { Dimensi } \\
\text { pelontarTab } \\
6 \mathrm{U} \\
\mathrm{P}=366 \mathrm{~mm} \\
\mathrm{~L}=226 \mathrm{~mm} \\
\mathrm{~T}=113 \mathrm{~mm}\end{array}$ \\
\hline $\begin{array}{l}\text { Spesifikasi } \\
\text { material } \\
\text { pelontar }\end{array}$ & $\begin{array}{l}\text { Hard anodized } \\
\text { aluminium tipe } \\
\text { ASTM 7075- } \\
6061\end{array}$ & $\begin{array}{l}\text { Hard } \\
\text { anodized } \\
\text { aluminium } \\
\text { tipe ASTM } \\
5052-6061 \\
\end{array}$ \\
\hline $\begin{array}{l}\text { Spesifikasi } \\
\text { sistem } \\
\text { pelontaran } \\
\text { berbasis } \\
\text { tab }\end{array}$ & $\begin{array}{l}\text { Rel dengan } \\
\text { mekanisme } \\
\text { pegas }\end{array}$ & $\begin{array}{l}\text { Tab dengan } \\
\text { Actuator } \\
\text { menggunakan } \\
\text { servo dc } \\
\text { motor listrik } \\
\text { dan } \\
\text { Separation } \\
\text { Electrical } \\
\text { conector } \\
\text { DB15 dan } \\
\text { DB9 }\end{array}$ \\
\hline $\begin{array}{l}\text { Spesifikasi } \\
\text { sistem } \\
\text { kelistrikan }\end{array}$ & Tidak tersedia & $\begin{array}{l}\text { Tegangan } \\
\text { kerja } \\
\text { pelontaran } 22 \\
\text { Vdc dan arus } \\
\text { listrik actuator } \\
\text { separasi } 5 \mathrm{~A}\end{array}$ \\
\hline
\end{tabular}

Sumber: data diolah, 2019

\begin{abstract}
Berdasarkan tabel diatas diketahui informasi bahwa terdapat kesenjangan beberapa parameter teknis dalam standar acuan. Kondisi ini dapat diasumsikan bahwa perameter teknis berdasarkan kebutuhan stakeholder belum dipersyaratkan dalam ISO 17770:2017, namun sangat berpengaruh terhadap performansi produk pelontar satelit kubus berbasis tab. Hal ini terlihat dari masih ditemukannya spesifikasi teknis yang dipersyaratkan dalam dokumen teknis (data sheet) pelontar satelit $6 \mathrm{U}$ berbasis tab.
\end{abstract}

\section{KESIMPULAN}

Berdasarkan hasil analisis dan pembahasan di atas diperoleh kesimpulan bahwa terdapat 4 (empat) parameter teknis yang menjadi prioritas untuk disyaratkandalam penyusunan Standar Nasional Indonesiaproduk pelontar satelit kubus berbasis tab yaitu spesifikasi dimensi pelontar, spesifikasi sistem pelontaran, spesifikasi sistem kelistrikan pelontar dan spesifikasi material pelontar.

\section{DAFTAR PUSTAKA}

CubeSat Design Spesification (CDS). (2016). $6 \mathrm{U}$ CubeSat Design Spesification, Rev.13 Provisonal, California Polytechnic State University,2016.

DwiMandaris, Prayoga Bhakti, Hari Tjahjono. (2014). Karakteristik Kompor Gas Berbahan Bakar DME (Dimethyl Ether) Berbasis SNI 7368:2011. Jurnal Standardisasi Volume 16 Nomor 1, Hal 7-16.

E. Kullu. (2019). Nanosatellite Database. http://www.nanosats.eu.

International Organization for Standardization (ISO). (2017). ISO 17770:2017 Spacesystems - Cube satellites (CubeSats), Geneva, Switzerland.

Isaac Nason, J.Puig-Suari, Robert Twiggs, (2002). Development of a family of picosatellite deployers based on the CubeSat Standard, Aerospace Conference, IEEE Proceedings, San Luis Obispo,CA, USA.

Jimmy Pusaka. (2011).Analisis Isi ISO/IEC 17025 Bagi Laboratorium Metrologi. Jurnal Standardisasi Volume 13 Nomor 1, Hal 67-71.

J.Puig-Suari, C.Turner, and W.Ahlgren. (2100). Development of the standard CubeSat deployer and CubeSat class picosatellite. 2001 IEEE Aerospace Conference Proceedings, pp. 347-353, Big Sky, MT, USA.

Lucas Pratt, Emily Nightingle, Asha Balakrishnan. (2015). The Cubesat Ecosystem: Examining The Launch Niche. $66^{\text {th }}$ International Astronautical Congress, Jerusalem, Israel.

Ryan Hevner and Walter Holmans. (2011). AnAdvanced Standard for CubeSats. $25^{\text {th }}$ Annual AIAA/USU Conference on Small Satellites, Utah State University, USA.

Rizki Amalia Pratiwi, Fakhrina Fahma, Wahyudi Sutopo, Eko Pujianto, Suprapto, Meilinda Ayundyahrini. (2018). Usulan Kerangka Standar Kursi Roda Manual Sebagai Acuan Penyusunan Standar Nasional 
Indonesia (SNI). Jurnal Standardisasi Volume 20 Nomor 3, Hal 207 - 217.

Stephen K. Tullino, Eric D. Swenson. (2017). Testing and Validating Deployment Profiles of the Caniterized Satellite Dispencer (CSD). $31^{\text {st }}$ Annual AIAA/USU, Conference on Small satellites, SSC17-P2-25, Utah State University, USA.

Teguh Pribadi A.N, Ellia K. (2012). Pengembangan SNI Kompor/Tungku Masak Bersih. Jurnal Standardisasi Volume 14 Nomor 3, Hal 206 - 217.

Walter Holmans, Ryan Williams. (2014). Caniterized Satellite Dispencer (CSD)
As a standard for integrating and dispensing hosted payloads on large spacecraft and launch vehicles. $30^{\text {th }}$ Space Symposium, Technical Track, Colorado Springs, Colorado, USA.

Pemerintah Indonesia. (2013). Undang Undang Nomor 13 Tahun 2013 Tentang Keantariksaan.

Pemerintah Indonesia. (2017). Peraturan Presiden Nomor 45 Tahun 2017 Tentang Rencana Induk Penyelenggaraan Keantariksaan tahun 2016-2040. 
